\title{
Ensaio sobre o livro "Admirável Mundo Novo" de Aldous Huxley: uma proposta crítica contemporânea
}

\author{
Essay on the book "Brave New World" by Aldous \\ Huxley: a contemporary critical proposal
}

Ricardo Marinho Silva

Universidade de Évora (Évora). Portugal. ricardomarinho.ufba@outlook.com

RESUMO | Em tempos de grande avanço tecnológico e retrocessos no que se refere a aspectos humanos, o "Homo" descrito pela Biologia como "Sapiens" evolui para "Homo Maquinizado". Essa nova configuração do homem regida pela Ciência, Tecnologia, Capitalismo e Globalização se reflete num novo paradoxo humano: a supervalorização da economia em detrimento da vida, impactando nas relações/configurações do viver. Dessa forma, o presente ensaio tem como objetivo fazer uma análise crítica do livro "Admirável Mundo Novo" de Aldous Huxley, que discute a relação homem que cria um sistema, e, que, quando atravessado pela sua criação, torna-se seu próprio produto no ciclo de se produzir. O livro “Admirável Mundo Novo" trata-se de uma parábola que romantiza a desumanização dos seres humanos. Identifica-se que, desde a sua primeira publicação em 1932, o mundo afundou-se a passos tão largos em direção errada semeando o mercantilismo da vida e a cultura da competitividade que corrói a sociabilidade e destrói os sentimentos intrínsecos da sociedade humana que, se o autor escrevesse hoje a mesma obra, a ficção não estaria a seiscentos anos do presente. E a consequência da liberdade, ou melhor, da simples humanidade, teria se revelado desumana.

PALAVRAS-CHAVE: Humanidade. Capitalismo. Globalização.

\begin{abstract}
In times of great technological advancement and setbacks regarding human aspects, the "Homo" described by Biology as "Sapiens" evolves into "Homo Machined". This new configuration of man governed by Science, Technology, Capitalism and Globalization is reflected in a new human paradox: the overvaluation of the economy at the expense of life, impacting the relationships / configurations of living. Thus, the present essay aims to make a critical analysis of the book "Brave New World" by Aldous Huxley, which discusses the relationship between man who creates a system, and which, when crossed by its creation, becomes its own product in the cycle of producing. The book "Brave New World" is a parable that romanticizes the dehumanization of human beings. It is identified that, since its first publication in 1932, the world has sunk so far in the wrong direction sowing the commercialism of life and the culture of competitiveness that it erodes sociability and destroys the intrinsic feelings of human society that, if the author wrote the same work today, fiction would not be six hundred years from the present. And the consequence of freedom, or rather, of simple humanity, would have turned out to be inhuman.
\end{abstract}

KEYWORDS: Humanity. Capitalism. Globalization. 


\section{Introdução}

Somos selvagens ou civilizados? Dilema "moral-ético-humano" que nos coloca a pensar sobre até que ponto os seres são biologicamente inatos ou socialmente condicionados (Pinheiro, 1994; Carvalho Neto, 2003; Zuanon, 2007). Em "Admirável Mundo Novo", livro escrito por Aldous Huxley, discute-se acerca da padronização do produto humano - a relação do homem com o mundo, na perspectiva de que antigamente o homem criava máquinas. Entretanto, atualmente, tornou-se escravizado por elas.

Aldous Leonard Huxley (1894 - 1963) foi um escritor e filósofo inglês. Formado em literatura inglesa pela Universidade de Oxford, produziu roteiros de filmes, poesias, ensaios e livros. Suas influências se iniciaram desde a infância com seu avô, o biólogo Thomas Henry Huxley e sua mãe, a romancista Humphrey Ward. Na Universidade, Aldous Huxley teve contato com o escritor britânico Lytton Strachey e o filósofo Bertrand Russell e produziu outras obras como "A porta da decepção", "A ilha" e "A filosofia perene".

Em seu livro "Admirável Mundo Novo", lançado em 1932, na Inglaterra, ano de grandes consequências sociais na crise da grande depressão que fragilizava as estruturas económicas e consequentemente a vida produtiva na europa. Narra-se a história que decorre num futuro não muito distante, próxima ao ano 2500 ou, mais precisamente "no ano 600 da Era Fordiana", fazendo alusão a fé científica positivista e a Henry Ford, criador da indústria automobilística e inventor de um método de organização de trabalho para a fabricação em série e padronização de peças. Resultando-se em uma sátira à cultura capitalista e o seu movimento que buscava que o consumismo subjetivasse as formas de viver a vida.

A partir da industrialização e seus meios exacerbados de produção, a sociedade adquiriu novas estruturas de funcionamento, nomeadamente numa lógica mercantil. Com a evolução das grandes tecnologias, transitamos do sistema industrial e começamos a pensar num novo formato de homem: homem individual, da sociedade globalizada e munida de excessos de tecnologia (Bauman, 2009, p.7). Tal formato político-económico não se restringe ao comércio e ao dinheiro unicamente, mas, estabelece como novo formato de vida a lógica produtiva-consumista (Medeiros, 2004; Fleury, 2018).
Fruto do sistema do capital que gera indivíduos que em ciclo buscam, de maneira equivocada, aquilo que não sabem como obter, mas a busca os coloca em movimento, respondendo de maneira adoecida. O capitalismo e a globalização criam novas formas de crença em que adquirir uma vida feliz baseia-se em adquirir bens no "aqui e agora" e essa mudança reflete-se de maneira subjetiva na sociedade (Han, 2015). A influência do capitalismo-mercantilismo-positivismo científico é tamanha que transformou a capacidade de expansão da racionalidade e reflexão crítica humana em padrões formatados a pensar a vida como se fossem máquinas com poucas emoções humanas (Hugo Dias, 2011; Corbanezi, 2018; Viapiana, 2018; Marinho, 2019; Gurgel, 2019; Ferraro, 2019).

O homem que trabalhava em excesso para sobreviver ao mundo do consumo passa a não suportar as vantagens do neoliberalismo acompanhado a ele o triunfo da racionalização em detrimento do subjetivo, o predomínio da razão: cultural, tecnológica e científica e a nova forma de viver uma vida de consumo (Han, 2015). A alteridade culturalizou-se no cancelamento do outro e os modelos de funcionamentos extremistas, competitivos e violentos sobrepõem os movimentos coletivos-cooperativistas e seus efeitos na subjetividade em um novo cenário socio-político-cultural, que provoca, em paralelo, desigualdade, segregação, intolerância, crescimento alarmante da poluição, danosas mudanças climáticas, centralização do capital e incentivo às desigualdades sociais (Bauman, 2001; Han, 2015).

Em consequência, o sistema entrou em colapso (Calderón Gómez, 2017), como aponta Botelho (2019), trata-se de uma crise estrutural, e as medidas castradoras e coercitivas colocadas à humanidade de tornarem a felicidade como fruto de poder ligado à aquisição de bens. Isso obriga os indivíduos a trabaIharem de formas exaustivas em nome da busca de felicidade e qualidade de vida, criando escravidões de maneira assalariada, o que se reflete em demandas excessivas de trabalho e tempo reduzido para viver a vida (Foucault, 1987; Deleuze, 1992; Han, 2015; Calderón Gómez, 2017; Botelho, 2019).

Contextualizando, tal método, nomeado como "fordismo", subjetivou os trabalhadores em algo inferior a autômatos, robôs que repetiam, ao longo da jornada de trabalho, um único gesto (Moraes Neto, 1986; 
Moraes Neto, 2009). No livro, o que se nomeia como Estabilidade Social consiste em "Homens e Mulheres padronizados, em grupos uniformes. Todo o pessoal de uma pequena usina constituídos pelos produtos de um único ovo bokanovskizado." (p.10). Trata-se de uma crítica ao culto positivista e à ciência experimental, num momento em que as consequências sociais afetam a sociedade e a crença no progresso e nos regimes democráticos parecem desaparecer para eleger milícias totalitárias. Em formato de premeditação, seu prefácio é datado trinta e cinco anos após a escrita original do livro. $O$ que nos coloca a pensar que o autor, ao satirizar "Oh Ford!" (p.22) em todo o escrito, referiu-se à construção de um sistema constituído para moldar a vida em produto humano, tornando o livro visionário naquela época.

Entretanto, em tempos de grandes avanços tecnológicos, em contexto pós globalização, o admirável mundo continua a ser novo? Dessa forma, o presente estudo aborda os efeitos do capitalismo e globalização em 2020 contrastando com um livro que narra tais eventos sob o olhar de 1932. Buscando responder à problemática em questão, o presente ensaio crítico tem como objetivo analisar o livro "Admirável Mundo Novo" de Aldous Huxley, trazendo um olhar crítico-reflexivo a partir dos novos moldes da sociedade atual. $O$ trabalho não se focaliza na transcrição de fatos exatos, mas, a relevância científica e social se assume do ponto de vista crítico, descrevendo padrões de funcionamentos macro e microssociais. Espera-se que a partir da reflexão, abram-se novos horizontes nos permitindo outros olhares e, com isso, se alterem o sentido das coisas.

\section{Aspectos Metodológicos}

O presente ensaio teórico faz uma análise crítica, sob o recorte temporal contemporâneo, tendo como objeto de investigação o livro "Admirável Mundo Novo", de Aldous Huxley, publicado em 1932. Por se tratar de uma metodologia qualitativa, sob o recorte metodológico de um ensaio teórico, busca-se apresentar a interação entre a objetividade teórica com a subjetividade analítica que compõe a análise crítica (Meneghetti, 2011). O conhecimento científico organiza-se a partir das multiplicidades, cujo objetivo da ciência é de elaborar modos de leituras e discursos da realidade (Daltro e Faria, 2019). Com essa perspectiva, o trabalho se detém a apresentar um conjunto de saberes apreendidos pelo olhar do pesquisador, que em lugar de escrever verdades, busca descrever reflexões para que novos fluxos de conhecimento se construam. O processo de análise crítica é um processo de releitura interpretativa que reorganiza narrativas à luz de novas teorias desenvolvidas, dando possibilidades de tecer novas configurações de saber e, consequentemente, de produzir outras marcas históricas.

\section{Resultado e Discussão}

Seguindo o Lema planetário do "Admirável Mundo Novo": - "Comunidade, Identidade, Estabilidade." (Huxley, 1931. p.8). Resultando numa sociedade totalitária, fascinada pelo progresso científico e convencida de poder oferecer aos seus cidadãos uma felicidade obrigatória. A sociedade, ou melhor, o sistema tende a funcionar esquematizado por castas.

Decantamos nossos bebês sob a forma de seres vivos socializados, sob a forma de Alfas ou de ipsilons, de futuros, carregadores ou de futuros Administradores Mundiais - Diretores de Incubacão. (Huxley, 1931. p.13)

Dessa maneira, dá-se a construção do homem de forma padronizada, de forma maquinizada, através de métodos que o farão ser. Perde-se o romantismo e a individualidade da maternagem - processo biológico e físico o qual está implicada a "díade mãe-bebê", pressupondo-se que interações sociais são fatores importantes para o desenvolvimento humano (Vygotsky, 1984), para haver um processo de construção de humano ideal, que produza num ciclo sem fim, de forma a construir uma sociedade produtiva. Haja vista, como aponta Huxley (1931), o processo de maturação em formato de produção, torna o homem-homem social (pouco socializável) para atender às demandas da vida. A ciência e a tecnologia seriam usadas como se tivessem sido feitas para o homem, entretanto, ocorre como se o homem tivesse sido escravizado por elas. 
À vista disso, o livro transmite a ideia de que a sociedade é pragmaticamente moldada. Não há livre arbítrio. Na verdade, há um condicionamento que faz as pessoas tornarem-se o que elas são. Isso permite a sociedade funcionar, entretanto seu funcionamento é artificial, hierárquico e desigual. As castas limitam os indivíduos da potencialidade que lhes é inerente, é humana. A humanidade tornou-se reflexo do modelo fordista de produção e as especificidades que deveriam ser aperfeiçoamento, tornam-se completude.

À medida que diminui a liberdade política e econômica, a liberdade sexual tende a aumentar em compensação." [...] "Nosso Freud foi o primeiro a revelar os perigos espantosos da vida familiar. $O$ mundo estava cheio de pais - e, em consequência, cheio de aflição; cheio de mães - e, portanto, cheio de toda espécie de perversões, desde o sadismo até a castidade; cheio de irmãos e irmãs, de tios e tias cheio de loucura e suicídio. (Huxley, 1931. p.7)

Michel Foucault em seu livro "Vigiar e Punir" (1987), aborda que as instituições foram criadas para controle social. Segundo Ramos \& Nascimento (2008), a família é a primeira instituição social - como diria em "Admirável Mundo Novo", sala de "predestinação social", que prepara o indivíduo para a sociedade.

Toda instituição é uma ferramenta de socialização criada pelo próprio homem com a função de gerenciar suas relações interpessoais. A instituição normatiza, legaliza, legitimiza os comportamentos do indivíduo em sociedade. Ela também é geradora de estabilidade

e segurança nas trocas sociais. Sendo a família uma instituição, ela se apresenta como a primeira instituição com a qual o indivíduo tem contato em sua vida.

(Ramos e Nascimento, 2008).

Segundo Elisabeth Badinter, em seu livro "Mito do amor materno" (1985), tal responsabilidade é imposta histórica-culturalmente ao sexo feminino. Dessa forma, a construção do indivíduo em "Admirável Mundo Novo", des-romantiza os laços familiares afetivos, dando total responsabilidade ao Estado por eles, que trata de maneira maquinizada os efeitos que o social ensinou nas relações. O que há de novo ao tratar-se de admirável? Em Foucault (1987) e sua teoria dos "Corpos Dóceis" identifica-se uma denúncia de um sistema que cria uma sociedade controlada e o remédio para uma sociedade que não se tem controle, portanto, é a loucura, citando o livro "Selvagens".
Não se pode ensinar habilidades a um rinoceronte - explicou ele no seu estilo conciso e vigoroso. - Há homens que são quase rinocerontes, não reagem de maneira adequada ao condicionamento. Pobres coitados! Bernard é um desses. (Huxley, 1931. p.53)

Entretanto, o diálogo entre o personagem Bernard e a personagem Lenina apresenta-se como uma ruptura ao condicionamento, "um pensar livre" do que a sociedade impôs que ambos pensassem, "um pensar só por pensar" que destoava do que os condicionamentos traziam como normalidade, porque Bernard questionava o sistema que para Lenina se apresentava como natural - era único modelo e tido como normal. Platão, em seu "Mito da Caverna", acreditava que cada indivíduo só conseguia enxergar aquilo que o seu próprio reflexo permitia (2001), ou seja, ambos se tornaram reflexo-identidade, máquinas, daquilo que a sociedade deu como utilidade.

A sensação de ser mais eu, se é que você compreende o que quero dizer. De agir mais por mim mesmo, $e$ não tão completamente como parte de alguma outra coisa. De não ser simplesmente uma célula do corpo social." [...] "Como posso? Não, o verdadeiro problema é este: Como é que não posso, ou antes - porque eu sei perfeitamente por que é que não posso - o que sentiria eu se pudesse, se fosse livre, se não estivesse escravizado pelo meu condicionamento? (Huxley, 1931. p.55)

No entanto, será que sem os condicionamentos - até então utilizados em Psicologia experimental, como por exemplo Pavlov e Skinner, não se trata de cessação e liberdade? “...e que era a expressão da censura da própria Sociedade." (Huxley, 1931. p.59)

Com base no livro surgem os seguintes questionamentos: era esse o caminho que os personagens gostavam de seguir com as suas próprias vidas? Somos livres? Até que ponto não somos seres condicionados, pelo social, a sermos o que somos? Liberdade de expressão? Intervenção militar? Bullying? Discriminação? Somos seres criticamente pensantes ou refletimos aquilo que a "globalização", ou seja, redes sociais e os grandes meios de comunicação nos subjetivam a pensar? O livro "Admirável Mundo Novo" (Huxley, 1931. p.59) nos responde que é preciso abolir qualquer espécie de liberdade porque ela traz consigo o caos. 
O "livre arbítrio", quando associado ao conceito de individualidade que teve função estrutural para a modernidade, traz consigo os interesses individuais em sobreposição do bem coletivo, a cultura da competitividade e, consequentemente, a guerra (Calhau, 2016). No livro é citado que nem todos podem ser "Alfas" ou somente "Ipsilons", e reflete sobre a importância da alteridade e dos papéis sociais para o funcionamento da sociedade. Entretanto, somos colocados a pensar, em sociedades desiguais, estratificar entre Alfas e Ipsilons resolve a instabilidade social? (Karl Marx, 2007).

Zygmunt Bauman no livro "Modernidade líquida" (2001), descreve que o capitalismo exacerbado e toda a sua forma de produção em massa trará consequências à humanidade. Consequências que desde a Revolução Industrial, como elucidado nos filmes do Charles Chaplin, mostram como moldaram os humanos a trabalhar como se fossem máquinas, consumir como se fossem produtos, funcionando como alimento do ciclo do capitalismo.

A luz de Huxley (1931), caminhamos passos para a desumanização da sociedade e sua forma de viver individualista - competitiva. Caracterizadas por serem centradas em si, em suas próprias casta, sem capacidade de enxergar castas inferiores, sem esboçar nenhum sentimento para as pobrezas e misérias das castas outras. Pois, segundo "Admirável Mundo Novo", a sociedade foi condicionada a tratar do sofrimento humano daqueles que são diferentes com desumanidade.

Coincidentemente, a sociedade se depara com o crescente e alarmante uso de substâncias que elevam a capacidade produtiva (Ortega, et al., 2010). Segundo dados da Agência Nacional de Vigilância Sanitária, em 2010 foram vendidos 2,1 milhões e em 2013, foram 2,6 milhões de caixas metilfenidato (Anvisa, 2013), substância estimulante do sistema nervoso central utilizada para melhorar a performance intelectual. Dessa forma, as substâncias, ou seja, os remédios cujos ideais primitivos são para "curar", funcionam a serviço da "Sociedade de Controle" (Foucault, 1987), para produzir mais produtores - um ciclo do capitalismo que não tem fim, levando o humano a uma sociedade adoecida, porém medicalizada (Han, 2015).
Haja vista, com as formas de controle, dessa vez subjetivas, que autorizam o Estado como aquele que protege a vida; e do saber médico como aquele que assegura a vida, as criações das leis e manuais diagnósticos funcionam como um "saber-poder" perante a sociedade (Foucault, 1987). Que em parceria com as grandes estruturas de marketing das massas, como por exemplo as indústrias farmacêuticas, capitalizam a vida a responder, funcionando sob a lógica de produção. Fabricando sujeitos, humanos padronizados, adoecidos, porém que funcionam no combate e erradicação daquilo que não pode ser lucrável.

Pensando que os antidepressivos e ansiolíticos não solucionam a complexidade dos efeitos dos condicionamentos humanos em máquinas de produção. Entretanto, devido à grande quantidade de tóxicos de tais substâncias, e, consequentemente, seu demasiado efeito negativo sob a produção, o "estado totalitário" utiliza de políticas proibicionistas - estratégias de controle, cujo objetivo recai novamente em mercantilizar a liberdade humana. Porém, no livro, o autor pensou além, ironizando o homem projetado para atender as demandas do mercado, quando recomenda para os cientistas da contemporaneidade a ideia da "Soma", a droga que, segundo "Admirável Mundo Novo", traz a quantidade exata de felicidade, somando em produtividade.

Não se pode fazer uma tragédia sem instabilidade social. O mundo agora é estável. As pessoas são felizes, têm o que desejam e nunca desejam o que não podem ter. Sentem-se bem, estão em segurança; nunca adoecem; não têm medo da morte; vivem na ditosa ignorância da paixão e da velhice; não se acham sobrecarregadas de pais e mães; não têm esposas, nem filhos, nem amantes, por quem possam sofrer emoções violentas; são condicionadas de tal modo que praticamente não podem deixar de se portar como devem. E se por acaso alguma coisa andar mal, há o soma. (Huxley, 1931. p.127)

Lipovetsky em seu livro “Felicidade Paradoxal: ensaios sobre a sociedade do hiperconsumo" (2007), aborda o paradigma do homem em busca da compra da felicidade. Homem - Consumo - Mundo (Bourdieu, 2001), perspectiva que acredita que o homem enquanto ser social foi subjetivado, ou seja, condicionado a se comportar num ciclo de produzir para consumir e o ser 
feliz está associado às possibilidades que o capitalismo oferece. Dessa forma, a razão da vida humana se limita às fronteiras que a moeda local pode oferecer, criando-se, assim, um sistema cruel e reducionista, pois limita o sentido da existência àquilo que o funcionamento positivista-capitalista pode oferecer.

\section{Reflexão Final}

Em “Admirável Mundo Novo", a soma é a droga da felicidade que faz dormir. Não diminui a produtividade e não traz consequências ao Homem. A partir disso, discute-se a concepção contemporânea de que na vida a felicidade é colocada como meta, sob ideologia meritocrática de que só precisa se esforçar e após abdicação e longo trabalho, será recompensado em que a recompensa é ser feliz. Pois, neste ciclo, a vida é posta como um objetivo a ser conquistado e o conhecimento/dinheiro são potenciadores. Atualizando a teoria da "virtude" em "A República" do autor Platão, o poder trará, consequentemente, a felicidade.

No entanto, numa sociedade em que "as horas custam dinheiro" e o excesso de informação sobrecarrega a vida, o homem que estudou séculos para a Artificial Intelligence cometeu o erro de aprofundar pouco o estudo acerca de si mesmo. À vista disso, o "Homem é sobrecarregado a desempenhar sua condição de multitarefa comandado pelo excesso de trabalho no formato de autoexploração. Os ideais de individualidade trazem consequências individualistas para a contemporaneidade: de tanta inteligência, o homem tornou-se frio, como o livro do autor Aldous Huxley descreve: tornou-se - não no sentido de não civilizado, mas sim, no sentido de des-humano. E a ficção descrita em "Admirável Mundo Novo" tornou-se real no "Admirável Mundo do Agora". Discutido em capítulos dos jornais diários, vemos na mídia televisiva a crescente violência, fruto da política ditatorial e a lógica de vida mercantilista de castas, sob o formato "blasé" em "Admirável Mundo Novo" - porém, real. O assujeitamento do humano em detrimento do sistema evoluiu-se a passos tão largos que a preocupação é com os efeitos à humanidade. O discurso do Selvagem que encerra o livro nos coloca a pensar que mesmo os seres - racionais - pensantes, condicionados pelas estratégias de controle do marketing social, nos trouxeram até o discurso da Greta Thunberg à Organização das Nações Unidas. "O admirável mundo novo do agora" está a acabar e ninguém faz nada. Oh Ford.

\section{Conflitos de interesses}

Nenhum conflito financeiro, legal ou político envolvendo terceiros (governo, empresas e fundações privadas, etc.) foi declarado para nenhum aspecto do trabalho submetido (incluindo, mas não se limitando a subvenções e financiamentos, participação em conselho consultivo, desenho de estudo, preparação de manuscrito, análise estatística, etc.).

\section{Referências}

Agência Nacional de Vigilância Sanitária (2013). Estudo aponta crescimento no consumo de metilfenidato [Internet]. Recuperado de: https://bit.ly/2B6ul72

Badinter, E. (1985). Um amor conquistado: o mito do amor materno (W. Dultra, Trad.). Rio de Janeiro: Nova Fronteira.

Bauman, Z. (2001). Modernidade líquida. Rio de Janeiro: Jorge Zahar Editor.

Bauman, Z. (2009). A arte da vida. Rio de Janeiro: Jorge Zahar.

Bourdieu, P. (1989). O poder simbólico. Rio de Janeiro: Bertrand Brasil S.A.

Bourdieu, P. (2001). Sobre o poder simbólico. In: P. Bourdieu. O Poder Simbólico (F. Tomaz, Trad.). Rio de Janeiro: Bertrand Brasil.

Botelho, M. L. (2019). Superacumulação e colapso do capitalismo no Brasil em retrospectiva. Geografares, 28, 182-199. Recuperado de: https://periodicos.ufes.br/geografares/ article/view/24392. doi: 10.7147/GEO28.24392

Carvalho Neto, M. B., Salina, A., Montanher, A. R. P., \& Cavalcanti, L. A. (2003). O projeto genoma humano e os perigos do determinismo reducionista biológico na explicação do comportamento: uma análise behaviorista radical. Revista Brasileira de Terapia Comportamental e Cognitiva, 5(1),4156. Recuperado de http://pepsic.bvsalud.org/scielo. php?script=sci_arttext\&pid=S1517-55452003000100006

Gómez, D. C. (2017). Reseña/Review (Macías Vázquez, A., "El colapso del capitalismo tecnológico\&quot;. Madrid: Escolar y Mayo, ISBN 9788416020799, 232 págs., 2017). Teknokultura. Revista De Cultura Digital Y Movimientos Sociales, 14(1), 177-180. Recuperado de https://revistas. ucm.es/index.php/TEKN/article/view/56355. doi: 10.5209/ TEKN.56355

Calhau, F. R. F. (2016). Esanio Sobre Individualismo. Individualismo, uma alternativa ao (ego) centrismo. Espanha: Chiado. 
Corbanezi, E. (2018). Transtornos depressivos e capitalismo contemporâneo. Caderno CRH, 31(83), 335-353. Recuperado de https://www.scielo.br/scielo. php?pid=S0103-49792018000200335\&script=sci_ abstract\&tlng=pt. doi: $10.1590 /$ s0103-49792018000200011

Daltro, M. R., \& Faria, A. A. (2019). Relato de experiência: Uma narrativa científica na pós-modernidade. Estudos e Pesquisas em Psicologia, 19(1), 223-237. Recuperado de http://pepsic.bvsalud.org/scielo.php?script=sci_ arttext\&pid=S1808-42812019000100013\&lng=pt\&tIng=pt. doi: $10.12957 /$ epp.2019.43015

Deleuze, G. (1992). Post-scriptum sobre as sociedades de controle. In: Conversações (P. P. Pelbart, Trad.). Rio de Janeiro: Ed. 34.

Ferraro, M. R. (2019). Capitalism, slavery and the making of brazilian slaveholding class: a theoretical debate on world-system perspective. Almanack, (23), 151175. Recuperado de https://www.scielo.br/scielo. php?pid=S2236-46332019000300151\&script=sci_arttext. doi: 10.1590/2236-463320192307

Foucault, M. (1987). Vigiar e Punir: nascimento da prisão (L. M. P. Vassalo, Trad.). Petrópolis: Vozes.

Fleury, S. (2018). Capitalismo, democracia, cidadania contradições e insurgências. Saúde em Debate, 42(3), 108-124. Recuperado de https://www.scielo. br/scielo.php?script=sci_abstract\&pid=S0103$11042018000700108 \&$ Ing=en\&nrm=iso\&tlng=pt. doi: 10.1590/0103-11042018s309

Han, B. C. (2015). Sociedade do cansaço (E. P. Giachini, Trad.). Petrópolis: Vozes.

Gurgel, C., \& Marinho, M. (2019). Escravidão contemporânea e oyotismo. Revista Organizações \& Sociedade, 26(89), 317-337. Recuperado de https://www.scielo.br/pdf/osoc/ v26n89/1984-9230-osoc-26-89-317.pdf. doi: 10.1590/19849260896

David, H. (2010). The Enigma of Capital and the Crises of Capitalism. London: Profile Books.

Huxley, A. (1932 [1966 ed.]). Admirável Mundo Novo. Lisboa: Antígona.

Lipovetsky, G. (2007). A felicidade paradoxal: ensaios sobre a sociedade de hiperconsumo. (M. L. Machado, Trad.). São Paulo: Companhia das Letras.

Marinho, M. O., \& Vieira, F. O. (2019). A jornada exaustiva e a escravidão contemporânea. Cadernos EBAPE.BR, 17(2), 351-361. Recuperado de https://www.scielo.br/scielo. php?pid=S1679-39512019000200351 \&script=sci_arttext. doi: $10.1590 / 1679-395171623$ 